\title{
Coopetition between Taxi Passenger Transport and Passenger Car Rental Industries in Taiwan
}

\author{
Jui-Lung Chen ${ }^{1}$ and Hsuan-Yi Lee ${ }^{2}$
}

\begin{abstract}
At present, taxi passenger transport and passenger car rental industries offer passenger transport services with small-sized vehicles in Taiwan. These two industries overlap but have significant differences in their management and business models. Recently, the introduction of online car-hailing platforms (sharing-economy industries like Uber) into Taiwan has intensified the competition and conflicts between these two industries. Thus, the Taiwan government has amended the law to distinguish them from each other more clearly. This study adopted observation and case study methods for the analysis of competition and cooperation between these two industries in Taiwan. Lastly, it offered suggestions on the future development of the two industries, in the hope of providing reference for the fields across academia, industry and government.
\end{abstract}

JEL classification numbers: L98, R48.

Keywords: Taxi Passenger Transport Industry, Passenger Car Rental Industry, Sharing Economy.

\footnotetext{
1,2 Department of Business Administration, National Chin-Yi University of Technology, Taiwan, R.O.C.
} 


\section{Introduction}

Although taxi passenger transport and passenger car rental in dustries both provide passenger services with small-sized vehicles in Taiwan, their markets overlap despite their distinctive features. Taxi passenger transport is part of paratransit and the limitations imposed on the taxi industry are different from those on the passenger car rental industry. With the rapid development of the Internet and technology, fast-changing communication devices have been evolving, from beep pagers, first hand-held cellular phones, and 3G-network to IOT that is heatedly discussed currently. Such a crystallization of technological wisdom not only brings more convenience to our daily life but also poses huge challenges to traditional industries (Kuo and Chou, 2017). Thanks to the technological development, the operating model of the taxi passenger transport industry has changed from traditional roadside hailing, fixed-location scheduling, call centers with vehicle use radio paging and dispatch, and taxi hailing of convenience stores into currently used online taxi hailing, and car-hailing mobile apps like Uber, Lyft, SideCar and LINE Taxi. These emerging car-hailing services all bring convenience to our life (Kuo and Chou, 2017). However, the costs have increased sharply along with technological progress for practitioners. At first, the car dispatch could be completed easily by a wireless car machine. However, now every taxi fleeth as to independently develop a ride-hailing app for consumers. Those taxi practitioners without IT background could only turn to software development engineers for app development at a high expense. Also, due to cognitive differences between them as well as the high cost incurred by app update, revision, and database maintenance, such apps often do not get updated, for which the apps may fail to offer consumers a good user experience. Moreover, as every taxi fleeth as produced its own app, there are an excessive number of ride-hailing apps (Chen, Chou and Shi, 2017;Kuo and Chou, 2017). In addition, except for long-term car rental services, passenger car rental practitioners could hire designated drivers for lessees in regard to short-term car rental, which is referred to as "short-term rental with designated drivers" for airport shuttle services, business shuttle services, and chartered tours. A majority of passenger car rental practitioners serve enterprises, government agencies, travel agencies, and credit card companies (Kuo and Chou, 2017; Laws and Regulations Database, 2020).

With the emergence of sharing economy, American technology companies Uber and Lyft, and a Malaysian mobile ride-hailing AppGrab, all have promoted the idea that vehicle owners could provide idle seats for people in need; vehicle owners can make profits while passengers are able to get different riding experiences (CTCI Foundation, 2019). Such a business model was introduced into Taiwan in 2013 by Uber, which would offer consumers a kind of convenience that they had never experienced before. Different from apps that taxi practitioners entrusted to others to be developed independently, which often have multiple problems, the Uber app provides excellent user experience, which turned into a 
trend for a while. However, Uber raised a storm of protest from taxi practitioners and passenger car rental practitioners due to its provision of passenger services with white-label vehicles (i.e. private cars). Thus, it announced the suspension of taxi operation in Taiwan on Feb. 10 ${ }^{\text {th }}, 2017$ after massive fines from the Taiwan government (Huang, 2019). In 2016, Ministry of Transportation and Communications proposed a new operating model as "diversified taxis", regulating that non-yellow taxis were allowed to take orders via ride-hailing mobile apps, Internet and call centers but roadside taxi hailing and prior scheduling were not allowed, which was interpreted as the best solution to unlocking Uber (Wu, 2019). However, on April $13^{\text {th }}$ of 2017 , Uber chose to re-enter Taiwan market by cooperating with passenger car rental practitioners, providing its platform system to them. Its system enables the short-term designated driver services to have a higher utilization rate. At that time, Ministry of Transportation and Communications also agreed that such cooperation conformed to the existing law, which promoted the entrance of local online car-hailing platforms like Join Me and Call A Taxi into the passenger car rental industry. Taxi passenger service practitioners also started to work with online car-hailing platforms developed by technology companies like Uber Taxi, TaxiGo and Call Little Yellow, rather than using traditional car-hailing platforms developed by themselves (Huang, 2019). However, the Taiwan taxi practitioners held the view that such an operating model of the passenger car rental industry overlapped with that of the taxi industry, so they went to the street protesting against its influence on their livelihood. On Feb $26^{\text {th }}$ of 2019, Ministry of Transportation and Communications gave an advance notice on the amendment on Article 103-1 of Highway Act, also called "Uber Article", which greatly limited the business scope of the passenger car rental industry. As a consequence, the passenger car rental practitioners protested against this regulation. At the end of 2019, Uber claimed to cooperate with the taxi passenger transport service providers by offering them dispatch platforms (Wei, 2019).

The following questions contribute to the motivation of this paper: against the background of the changes in the taxi and passenger car rental industries caused by the technological impact or by the emergence of a new operating model, in which way the future relationship of the taxi and passenger car rental industries will develop, how much influence the passenger car rental industry's new operating model will have on taxis, what influence the diversified taxis will produce on passenger car rental practitioners, whether the new operating model of the passenger car rental industry could be called "sharing economy", what influence the Taiwan government has on the two industries, whether the consumers have the right to choose, which way is the most secure and cost-effective for consumers, etc. Along with a case study of Company A located in Taiwan, this study hopes to investigate the follow-up development and planning of the taxi and passenger car rental industries in response to technological changes, laws and regulations, and coopetition. First, this study explored the influence of the new operating model on the taxi industry to understand the old operating 
model of traditional taxi companies. After that, this research analyzed the impact of Uber's entry into Taiwan in 2012 on the taxi industry, and discussed whether the operating model of the announced cooperation between Uber and the rental industry on April 13 $3^{\text {th }}, 2017$ complied with the existing law. Moreover, this research compared the protection (insurance) of passengers (consumers or lessees) and passers-by. Adopting the observation and case study methods, this paper intends to analyze the industrial competition-cooperation between the taxi passenger transport and passenger car rental industries in Taiwan, after which it proposes suggestions on their future development, hoping to provide reference for the industry, government and academia.

\section{Literature Review}

\subsection{Taiwan Taxi Passenger Transport Industry}

Taiwan's taxi passenger transport industry refers to those who are passenger car rental providers within the area approved by the Directorate General of Highways, Ministry of Transport and Communications (Subparagraph 4, Paragraph 1, Article 34 of Highway Act, and Subparagraph 4, Paragraph 1, Article 2 of Regulations for Automobile Transportation Operators). The operating models of the taxi passenger transport industry include taxi agencies, personal taxi agencies, and taxi transportation cooperatives. The taxi passenger transport industry refers to the business that people provide passenger transport services with taxis and get paid for their service (Subparagraph 15, Paragraph 1, Article 2 of Highway Act). Based on Article3 of Regulations for Application for Approval of Taxi Passenger Transport Operators, the taxi passenger transport industry has to accept the entrustment and complete application procedures of taxi passenger transport services. Taxi drivers are those who have obtained professional driving licenses and applied for the registration qualifications to Police Bureau of the municipality directly under the Central Government or the county (city) where they would be working, and are allowed to find employment in the taxi passenger transport industry or to join taxi transportation cooperatives with drivers' certificates and auxiliary licenses (Laws and Regulations Database, 2020). In late 2016, Ministry of Transportation and Communications promoted diversified taxis and the taxi passenger transport industry shall offer a diversified taxi service as required by a specific consumption pattern. The diversified taxi passenger service mentioned before refers to taxi passenger transport services provided based on prior reservation via online platforms that integrate supply and demand information (Article 2 of Regulations for Automobile Transportation Operators). The fare rate of diversified taxis shall be set by the taxi industry within the certified range (Subparagraph 1, Article 11 of Regulations for Automobile Transportation Operators). However, diversified taxis are only permitted to accept the reservation of passengers; they shall not look for passengers on tour or schedule shifts waiting for passengers at taxi stands (Article 91 of Regulations for Automobile Transportation Operators). Moreover, Ministry of Transportation and 
Communications modified part of the Regulations on October $1^{\text {st }}, 2019$ to spare the diversified taxis the taximeter if being approved by the authorities (Laws and Regulations Database, 2020).

Taiwan's passenger car rental industry refers to those who rent passenger cars or small-sized vans to others (Subparagraph 5, Paragraph 1, Article 34 of Highway Act, and Subparagraph 5, Paragraph 1, Article 2 of Regulations for Automobile Transportation Operators). According to Article 99 of Regulations for Automobile Transportation Operators, the passenger car rental industry is classified into three types, i.e. Type A, B and C. Type A should operate as business organizations, set up domestic and foreign service networks for chain operation, and special counters to offer rental services in transport stations, terminals and stops like airports, wharves, railway and highway stations. Type B and Type C shall operate as companies or under a company. However, Type $\mathrm{C}$ is limited to no less than one-year lease of passenger cars or small-sized vans. The rule of "being affiliated to car agencies" exists in both passenger car rental and taxi passenger transport industries, which refers to the system that the vehicle providers own the vehicles and sign contracts with passenger car rental practitioners, providing vehicles for their use while passenger car rental practitioners have legal license plates and operation qualifications to do leasing business with the vehicle to make profits. The passenger car rental industry mentioned below in this study only includes business cases that passenger car rental practitioners provide passenger transport services through designated drivers. The passenger car rental industry refers to lessors rent passenger cars or small-sized vans to lessees; if the lessees need assistance in driving the rented vehicle, passenger car rental practitioners should be responsible for hiring designated drivers while the hired designated drivers shall conform to the regulations stipulated in Subparagraph 2, Paragraph 1, Article 100 of Regulations for Automobile Transportation Operators authorized by Article 79 of Highway Act: If the lessee of the passenger car rentals needs to hire a driver, the less or shall be responsible for hiring one who has the required professional passenger car driving license. For those who are foreign lessees, the hired designated driver shall have a good command of the foreign language...(Laws and Regulations Database, 2020).

\subsection{Issues of Governing Regulations}

According to Subparagraph 5, Paragraph 1, Article 34 of Highway Act, the passenger car rental industry refers to "those who rent passenger cars or small-sized vans to lessees for their use". As stipulated in Subparagraph 2, Paragraph 1, Article 100 of Regulations for Automobile Transportation Operators under Article 79 of Highway Act, the passenger car rental industry shall also employ designated drivers to provide passengers with transport services. In this way, the passenger car rental industry is allowed to step into the passenger transport business of the taxi industry and offer similar services via prior reservation. Subparagraph 4 and 5, Paragraph 1, Article 34 of Highway Act stipulate: "Subparagraph 4. Taxi passenger transport industry: the operators rent 
passenger cars and transport passengers within approved areas. Subparagraph 5. Passenger car rental industry: the operators rent passenger cars or small-sized vans to lessees for their own use. According to the analysis of Peng (2017; 2018), both the taxi passenger transport and passenger car rental industries seem to operate by lease. As for the legitimacy of the behaviors involved, the taxi passenger transport industry shall operate based on a "contractual" relationship to transport passengers while the passenger car rental industry shall operate based on a "rental" relationship. According to Subparagraph 2, Paragraph 1, Article 100 of Regulations for Automobile Transportation Operators under Article 79 of Highway Act: "If the lessee of the passenger car rentals needs to hire a driver, the lessor shall be responsible for hiring one who has the required professional passenger car driving license. For those who are foreign lessees, the designated driver shall have a good command of the foreign language..." Henceforth, the passenger car rental industry can also provide designated driving services for lessees in addition to renting vehicles for lessees' own use. In this way, the business scope of the passenger car rental industry not only covers the lease of objects (i.e. vehicles), but also includes passenger transport services, which is a "contractual" relationship. Moreover, Peng $(2017$; 2018) also pointed out that Subparagraph 5, Paragraph 1, Article 34 of Highway Act stipulated that the business scope of the passenger car rental industry shall be limited to renting vehicles for lessees' own use. However, it is possible that the lessees do have related demands, like chartered tours of foreign travelers or chartered taxis for wedding couples that need designated driving. Therefore, it is necessary to allow the passenger car rental industry to provide the service of designated driving, which means that the classified operation by Highway Act should be modified and designated driving should be added to its business scope in response to such demands. Simply changing the relevant provisions of Highway Act based on Regulations for Automobile Transportation Operators is not appropriate, for it may lead to conflicts with the legitimacy of authorized parent acts.

To fight against crimes and protect consumers' rights and interests, the passenger car rental industry competes with the taxi passenger transport industry because it is allowed to transport passengers. Moreover, Uber employs certain mobile app to offer online car-hailing services, which further causes the management issues of the automobile transport industry. To deal with the new business model brought by Uber, the authorities need to proactively investigate into it and publish appropriate management methods. For example, if they spot illegal activities involving unauthorized automobile transport or taxi passenger transport services, they shall perform penalty according to Paragraph 2 and 3, Article 77 of Highway Act. Also, it should resolve the law enforcement issues based on related administrative relief procedures to protect consumers' rights and interests. Governing provisions and controversy is as follows: since Ministry of Transportation and Communications has permitted the operation of the passenger car rental industry via prior reservation whereas it stipulated that the taxi passenger transport industry could also provide similar services via "prior 
reservation" (i.e. diversified taxi service). According to Article 6 of Administrative Procedure Law, which stated the legal principle of equality as "administrative acts shall not be treated differently without justifiable reasons", the passenger transport service provided via "prior reservation" for the two industries shall be supervised under the same management model and regulations, which conformed to the purpose of classified operation proposed by Paragraph 1, Article 2 of Regulations for Automobile Transportation Operators. In response to the participation of information platforms like Uber in the industry, Ministry of Transportation and Communications shall consider practitioners' demand for Internet information platforms that provide matchmaking between drivers and passenger transport services. In terms of looking for passengers on tour or passenger service reservation, the Ministry shall establish a clear and reasonable standard so that it will be easy for the practitioners in the taxi passenger and passenger car rental industries to follow, and the authorities will be able to enforce the laws accordingly to maintain the order of fair competition in the market and solve industrial disputes..." (Laws and Regulations Database, 2020).

\subsection{Sharing Economy}

Sharing economy made its appearance long before the rise of capitalism. At its early stage, due to insufficient platforms for exchanging and sharing resources or high costs incurred by platform maintenance, previous business models were called "business to consumer (B2C)", in which the transaction happens like this: entrepreneurs dominate the manufacturing of products, and then consumers choose and purchase the products freely. Moreover, the popularity of the network has played an indispensable role in the rapid development of the sharing economy in recent years (Kang and Huang, 2015).

Jeremy Rifkin, an economic and social theorist, named the economic activities that revolve around the community sharing platforms like Airbnb and Uber as Collaborative Commons in his book The Zero Marginal Society. However, Collaborative Commons has started to change the economic life mode of human organizations: a mixed economic system which consists of a capitalist market and collaborative commons to work and compete with each other in the same space. The capitalism exists to introduce all dimensions of human life into economic occasions, while the market only acts as a special meeting occasion where people exchange commodities with each other occasionally. Nearly every aspect of human life is connected with business transactions to some extent $(\mathrm{Gu}, 2015)$. At present, the passenger car rental industry has versatile uses: a passenger car can be reserved for family use, multiple designated drivers can be hired for one car so that idle vehicles can be used to provide passenger transport services to make profits, and vehicles can be offered to friends and relatives if necessary and even rented to others. However, taxis are confined to drivers with required qualifications, and the number of drivers for a taxi is also limited; except for qualified drivers employed by taxi companies, others are not allowed to drive taxis. Otherwise, Article 91 of Regulations for Automobile Transportation Operators 
would be violated: the operation of the taxi passenger transport industry shall comply with the following regulation... Subparagraph Seven. It is not permitted to hand over a taxi to those without valid professional driving licenses and registration certificates of driving passenger cars (Laws and Regulations Database, 2020). In Taiwan, as for Uber based on the concept of sharing economy, its business mode revolves around the full use of vehicles. Thus, it is understandable that why Uber has given the priority to cooperating with passenger car rental practitioners rather than taxi passenger transport practitioners after it had been judged illegal operation(CTCI Foundation, 2019).

\subsection{Status Analysis}

\subsubsection{Taxi Passenger Transport Industry}

The taxi passenger transport industry belongs to paratransit, while it is broadly regarded to "represent all the urban passenger transport vehicles between private cars and the traditional public transit with fixed routes and schedules" (Chang, 1999). It could complement public transit, for which taxi passenger practitioners are exempt from license and fuel taxes while the taxi passenger transport industry is subject to verification collection of tax. License plates of the taxi passenger transport industry are issued by the Directorate General of Highways, Ministry of Transportation and Communications according to the regulations of Highway Act and Regulations for Automobile Transportation Operators, and the number of license plates in each region to be issued is determined by the proportion of the local population to the local area. The number of taxi transportation cooperatives and taxi passenger transport practitioners also follows Paragraph 1, Article 39 of Highway Act and Paragraph 2, Article 91 of Regulations for Automobile Transportation Operators. Individual taxi passenger transport practitioners can apply for registration only when they meet the requirements, of which the strictest one is explained as follows: for the past three years, the applicant has been punished and recorded for the violation of Road Traffic Management and Penalty Act. (Paragraph 7, Article 93 of Regulations for Automobile Transportation Operators).

However, if taxi drivers have not obtained the qualification for the personal operation, their vehicles shall be owned by taxi passenger practitioners (even if the vehicles are for personal use, the owner of driving permits will remain under taxi passenger practitioners but will be marked "self-owned"). If such vehicles are reported by the public or fined by the police, taxi passenger practitioners will receive traffic tickets and pay the fine before collecting it from the driver. Henceforth, only when the police enforcement unit issues a ticket to the drivers who are caught red-handed or drivers owe taxi passenger practitioners a debt and the practitioners apply for the transfer of tickets in accordance with the contract, the points for driving violations will be recorded under the name of the drivers who commit the violations. Due to the charge and substantial affiliated relationship, establishing taxi transport cooperatives or engaging in individual taxi passenger transport is often the priority for the taxi industry. Currently, the 
number of individual taxi passenger transport applications is not limited as the total amount control stipulated in Paragraph 2, Article 91 of Regulations for Automobile Transportation Operators exists in name only. If taxi passenger practitioners are willing to offer individuals employment records and certify they pass the test for the professional registration certificate, individuals can get registration certificates from the police station, after which they maintain the annual inspection for six years, so they are able to switch to the individual taxi passenger transport industry. As long as taxi passenger practitioners are willing to provide individuals employment records and taxis for them to drive, there is no other way to check whether there is any actual business behavior during the period (Laws and Regulations Database, 2020).

\subsubsection{Business Model of Taxi Passenger Transport Industry}

Based on the company types, taxi passenger practitioners can be divided into companies and firms. As for taxi passenger practitioners, whether they choose to rent their vehicles to taxi drivers. hiring taxi drivers to drive their vehicles or renting their taxi licenses for self-owned vehicles(hereinafter referred to as "being affiliated to taxi agencies" or "affiliated"), all of them require the practitioners to provide employment records to taxi drivers, after which taxi drivers are qualified to obtain registration certificates and join the taxi passenger service industry (Laws and Regulations Database, 2020). In practice, taxi drivers need the employment record from taxi passenger practitioners. In fact, it does not have practical binding forces and control over the drivers who are affiliated to taxi agencies. Although the drivers' whereabouts can be tracked and controlled via a global positioning system (GPS), they are usually unwilling to pay the cost incurred by the GPS use and they feel they are monitored all the time with a GPS system in the taxi that they drive if they are affiliated to certain taxi agencies. Nevertheless, taxi passenger practitioners take the risk of assuming joint and several liability as employers as stipulated in Article 188 of Civil Law (actual cases include No. 2962 Judgment of Supreme Court in 1993 and No. 973 Civil Judgment of Taipei District Court in 2014). Actually, the taxi passenger practitioners usually operate more than one taxi agency. Since the firm has an unlimited liability in terms of accountability, the practitioners cannot evade from the joint and several liability if the employed drivers run into trouble. On the contrary, a taxi agency often takes a limited responsibility, which is no more than the amount of capital contribution. In this context, even if a taxi agency is demanded to take the joint and several liability, the worst scenario is that it goes bankrupt. Therefore, taxi passenger practitioners often transfer the ownership of licenses and distribute them to each agency, minimizing possible massive losses caused by the accidents (Peng, 2017; 2018).

\subsubsection{Taxi Passenger Transport Service Industry}

The taxi passenger transport service industry (hereinafter referred to as the agency) matches those who need a ride with the taxi passenger transport practitioners who 
get paid for their transport services from taxi riders. At first, passengers hailed a taxi through phone calls, and a vehicle was dispatched to pick them up by radio or by a car machine inside the vehicle. Recently, mobile apps have been introduced to each agency, and taxi drivers are dispatched via mobile phones rather than car machines and radio. The taxi passenger transport service industry has to pay the invoice tax and profit-seeking enterprise income tax normally as part of the dispatcher, while it also has a limitation on the business area like taxi passenger transport practitioners (Chen et al., 2017). The drivers belonging to taxi passenger transport practitioners can freely participate in the agency and accept the dispatch (who should have a car) except that the agency has some stakes or investment where only "affiliated" vehicles can join, and each taxi driver can join only one agency. The largest taxi agency in Taiwan is called Taiwan Taxi Co., Ltd, which introduced satellite dispatch technology (named as iCall) from Singapore ComfortDelGro to offer a fair matchmaking mechanism. The iCall system adopts GPS technology to balance the supply and demand of taxis, which can efficiently solve the problem of asymmetric information; Taiwan Taxi is the most well-known brand of Taiwan taxi agencies, the first one that introduced systematic dispatching. In recent years, many technology companies have developed dispatching system of taxi agencies to match passengers with taxi drivers via car machine and mobile phone, while the agency engages in marketing, packaging, seeking customers, and bidding to help more taxi drivers make a profit so that the agency make profits by charging dispatch and advertising fees (Hou, Lien and Chou, 2017).

As discussed before, the taxi passenger practitioners mainly get dispatch fees, and charge the advertising on their taxis and in the television of the car. The charge is currently set by each taxi agency. Several common ways include charging a monthly fee that ranges from NT \$200 to NT \$3,500, along with free dispatching times per month. If the number of free dispatches exceeds, the dispatch fee will be charged variably from NT \$10 to NT \$20 per time or 5\% to $20 \%$ of the fare each time. Other costs include cell phone bills, a monthly rent of car machines, and passenger insurance (Bureau of Transportation, Kaohsiung City Government, 2020).

\subsubsection{Passenger Car Rental Industry}

The operation of the passenger car rental industry aims to rent passenger cars to those who need while the passenger car practitioners are classified into Type A, B and C. Limited to operate as a company organization, Type A should set up domestic and foreign service networks for chain operation, and rent counters to offer rental services in transportation stations, terminals and stops like airports, wharves, railway stations and highway stations. The capital amount of Type A should exceed NT \$50 million with more than 100 new passenger cars when registered, and it is allowed to operate only as a "company". Type B and Type C of the passenger car rental industry shall operate as a company or under a company. However, Type $\mathrm{C}$ is only permitted to rent passenger car or small-sized 
vans based on a lease term that is no less than one year. The capital amount of Type B should exceed NT \$5 million with over ten new passenger cars whereas that of Type C should also exceed NT $\$ 5$ million but with over one new passenger car. When passenger car rental practitioners provide vehicles to the lessee and employ designated drivers that have professional licenses, the behavior is defined as transporting passengers with passenger cars; it is an industry that provides passenger transport services like the taxi passenger transport industry. Different from the taxi industry, passenger car rental practitioners are required to pay license and fuel tax, and passenger car rental companies are required to pay the profit-seeking enterprise income tax and invoice tax.

Although the cost for those who engage in the passenger car rental industry is higher than in the taxi passenger transport industry, the total amount of license plates for passenger car rental practitioners is not limited. In addition, the passenger car rental practitioners can operate in a more flexible business area and with more types of vehicles compared with the taxi industry. As for Type B, it only needs NT\$ 5 million and ten new cars to set an agency. Therefore, professional drivers who are reluctant to work for certain passenger rental practitioner often establish a passenger car rental agency of Type B, which is often a ready-made company(Laws and Regulations Database, 2020).

\subsubsection{Car-hailing Platform}

\subsubsection{Uber}

After Uber entered Taiwan market in 2012,it has engaged in the illegal matchmaking between private cars (or commonly known as white-label cars) and potential passengers. On December 16, 2016, the Legislative Yuan passed the third reading of "Amendment to Some Provisions of Highway Act" to stipulate that those who do not operate automobile or tram transportation legally shall be fined up to NT \$25 million and even be ordered to close businesses. Uber claimed to withdraw from Taiwan market on and after Feb10 ${ }^{\text {th }}, 2017$, and announced to return in cooperation with passenger car rental practitioners in April of that year. This time, Uber only provided its app and system for passenger car rental practitioners and passengers; passengers used the app to rent vehicles from the lessors. Moreover, according to Subparagraph 2, Paragraph 1, Article 100 of Regulations for Automobile Transportation Operators: "If the lessee of the passenger car rental industry needs to hire a driver, the lessor shall be responsible for hiring one who has the required professional passenger car driving license. For those who are foreign lessees, the designated driver shall have a good command of the foreign language..." Employing designated drivers who have professional licenses for passengers to drive the rented vehicle also conformed to the policy for Uber as required by Chen-Tan Ho, the Minister of Transportation and Communications: buying insurance, paying tax, and being subject to the management. On June 6, 2019, Ministry of Transportation and Communications announced in advance the addition of Article 103-1 of Highway Act, of which the fifth paragraph said: the cost shall be charged daily or hourly 
with a minimum rent time of one hour and shall not be evaded in the name of preferential prices or discounts... This amendment indirectly declaimed the end of the current cooperative business model of Uber and passenger car rental practitioners.

At the end of 2019, Uber started to work with taxi passenger practitioners. Uber also improved the way it cooperated with passenger car rental practitioners; it only provided the airport pick-up service at the price set within one hour of service. In addition, Uber was denounced for not paying the massive fine. Based on No. 141 Administrative Ruling of Taipei High Administrative Court In 2019, since Taiwan Uber, namely as TAIWAN YUBO CO., LTD. was registered in Taipei City, the penalty should have been issued by Highway authorities of Taipei Municipal Government whereas Directorate General of Highways had no jurisdiction over the "taxi passenger transport industry with in Taipei City", thus having no discretion to punish Taiwan Uber. Therefore, the punishment was revoked, but the case was still appealable (Kuo and Chou, 2017; Laws and Regulations Database, 2020; Wei, 2019; Wu, 2019).

\subsubsection{Join Me}

Join Me is an online car-hailing platform of Triumph Motor Service(hereinafter referred to as TMS), which was developed independently by Taiwan. TMS is famous in Taiwan for providing airport pick-up, towing, and airport VIP services. Join Me was established in 2015 and integrated the resource of existing car rental business practitioners earlier than Uber. Similarly, the app Join Me adopted the real-time car-hailing model; in 2018, it was officially launched to operate in Taipei City. However, when the Article 103-1 of Regulations for Automobile Industry was amended, Pei-Ti Yu, the founder of the app Join Me, said, "It's really ironic. We boast of Taiwan's local spirit and it is the most law-abiding ride-hailing platform. To comply with the enterprise's integrity, we cannot provide this service any longer." She declared to suspend the real-time ride-hailing project on May $1^{\text {st }}, 2019$ (Carnews, 2019). 


\section{Methodology}

Mainly focusing on the analysis of the current situations for the taxi and passenger car rental industries, this research investigated the current development of the two industries in Taiwan based on the data from the Department of Statistics, Ministry of Transportation and Communications and the operating models of the two industries. It collected data and explored the legitimacy of the cooperation among online car-hailing platforms, the passenger car rental industry and the taxi industry under current laws, and compares the strategies in response to newly produced online car-hailing service platforms in Taiwan and other countries and regions. This research further discussed the controversy and relationships among the government, passenger car rental industry, taxi industry, and online car-hailing platform operators through the observation, document analysis, and case study methods.

\subsection{Observation Method}

Through the participation in the operation of the taxi passenger transport industry and passenger car rental industry, the researcher of the present study got to know the industrial ecology of these two industries. Also, the researcher used online car-hailing platforms to offer passenger transport services so as to obtain the information about passengers, taxi driving, and the passenger car rental industry.

\subsection{Document Analysis}

Document analysis refers to a method to fully understand research questions by collecting literature data about related market information, survey reports, and industrial dynamics according to a certain research purpose or topic. The collected data should be extensive from diverse sources, which shall be summarized and analyzed in terms of its source, reason, background, influence and significance of each event. Literature data could be government reports, research of the business and commerce industry, file database, data of enterprise organizations, books, papers, periodicals, reports, and news (Neuman, 2000). This research collected related regulations and rules, amendment records, the literature on relevant research topics and purposes. It also compared and contrasted the relevant regulations of Taiwan and other countries. In this way, this research expected to investigate the industrial relationship between the taxi passenger transport and passenger car rental industries as well as the conflicts of law due to the changes in the two industries caused by technological transformation in each country. Afterwards, the paper discussed the future relationship between the two industries as well as proposed relevant suggestions. The collected data include news, papers, periodicals, and research reports in and out of Taiwan as well as the publications of relevant government authorities, books, web pages, and reports of the Legislative Yuan researchers, etc. 


\subsection{Case Study}

Yin(1994) defined the case study as a kind of social and scientific research, and further developed the topology of case study research design. Case studies always establish theoretical constructs and propositions through single or multiple cases, or build up the middle-range theory via empirical evidence based on a single case (Eisenhardt, 1989). As the relationship among the taxi industry, passenger car rental industry, and online ride-hailing practitioners varies in different countries and regions, the operating and management models of those countries are different from those of Taiwan although issues of online car-hailing platforms like Uber have happened in other countries. Hence, this research took Taiwan industry as an example for subsequent case studies, exploring the operation of online ride-hailing platforms like Uber, the passenger car rental industry, and the taxi passenger transport industry after the publication of the new amendment of Regulations for Automobile Transportation Operators. In addition, the study took passenger car rental practitioners, taxi passenger transport practitioners, and taxi transportation cooperatives in Taiwan as actual cases for study. Combined with the three methods above, this study proposed conclusions and suggestions to enable more people to know Taiwan transportation industry, and provided follow-up research directions, expecting to present the current status of the industries, propose solutions for involved parties and to avoid similar problems in the future.

\section{Case Study}

\subsection{Introduction of Practitioners}

At the early stage, Practitioner A ran a taxi passenger transport company with nearly 1,000 professional taxi drivers. The person in charge had been a professional manager of taxi transportation cooperatives and has actively transformed recently to set up a passenger car rental agency. With much experience in the transportation industry, A has cooperated with online car-hailing platforms, online delivery platforms, and passenger car rental practitioners in recent years. Practitioner A was willing to offer valuable experience in related industries, so this study took Practitioner A as a case to study, hoping to provide insights into the conflicts between the current situation and management rules of the industries as well as the future development of the industry.

\subsection{Development of Passenger Car Rental Industry and Online Ride-Hailing Platform}

\subsubsection{Online ride-hailing Platform Leading to a Sharp Increase in Passenger Car Rentals}

Since Uber's cooperation with rental practitioners in 2017, Practitioner A was also ready to join the new network market, who said: "After Uber announced to work with the passenger car rental industry, a number of rental companies and 'affiliated' leased car sprung up. Some passenger car rental practitioners established multiple companies to attract the drivers who are interested in buying 
'affiliated' cars. Every ten people set up a passenger car rental company, or the drivers gather ten to build such a company jointly. Even middlemen show up to match car agencies with drivers and get commission." Referring to the data from Statistics Network of Directorate General of Highways, Ministry of Transportation and Communications, this study found out the passenger car rental changes in five major operation areas, namely Taipei, New Taipei, Taoyuan, Taichung and Kaohsiung; the number of passenger car rentals has increased from April 2017. As revealed by Practitioner $\mathrm{A}$, the online ride-hailing platform Uber began to send messages to designated drivers of rental passenger cars through the mobile app, helping designated drivers transfer to diversified taxis and leading to the massive decrease in passenger car rentals in that month. The other four cities shared the same characteristic except that Taipei City showed notable differences. The different change pattern of Taipei City could be attributed to the fact that multiple large passenger car rental companies were based in Taipei and their license applications for the business in Taiwan were all under the jurisdiction of Taipei city. Thus, the number of rental passenger cars of Taipei was higher than other cities. That explained why the rental passenger car growth caused by online riding-hailing platforms was not obvious for Taipei despite a sharp decrease of rental passenger cars in September2019.

\subsubsection{Cooperation Mode of Passenger Car Rental Industry and Online Ride-Hailing Platform}

Designated driving services provided by passenger car rental practitioners were usually seen in airport shuttle services, chartered tour services and business shuttle services. Consequently, designated drivers mostly worked for enterprises, travel agencies, and governments. Passenger car rental practitioners usually make appointments with their clients, so they arrange the next-day pick-up route a day before. As short-distance pick-up is difficult to be arranged and the clients who demand short-distance pickup services often need to use a car on short notice, they rarely serve consumers with short-distance pick-up needs. When online car-hailing platforms work with the passenger car rental industry, the passenger car lessees should hand in certificate of good conduct (certificate of no criminal record), certificate of no hit-and-run record, professional driving license for designated drivers, and passenger car lease documents to log in online car-hailing platforms. After that, the designated drivers could choose passenger car rentals from the companies via mobile apps and accept dispatches based on prior booking. Online car-hailing platform operators are responsible for advertising, providing customers for passenger car rental practitioners and charging service fees on each ride. In terms of the relationship between passenger car rental practitioners and online car-hailing platforms, the latter acts as taxi passenger transport service providers to serve the former. However, the former does not have an industry similar to the taxi passenger transport service industry (car agency) to dispatch passenger car rental practitioners. 


\subsubsection{Tax Issues Brought by the Cooperation of Passenger Car Rental Industry and Online Car-Hailing Platforms}

Since the entrance of the online car-hailing platform Uber, tax issues have always been a concern for Taiwan citizens. Currently, a number of people still hold the view that Uber runs without paying the tax. According to the report of $\mathrm{Wu}(2017)$ : "Officials indicated that finally Uber would pay tax in full amount of the fare and meal expenses from Uber Eats, which means that in principle, Uber does not owe taxes after operating in a new model. However, the general audit would be used later to check whether there are misstatements or understatements in its tax documents." Therefore, during its cooperation with passenger car rental practitioners, Uber pays the tax in full amount of fare charged from the public. Based on Cross-border E-commerce Tax Regulation, passenger car rental practitioners shall issue the invoice (pronouncing 'fapiao' in Chinese) of full fare after deducting Uber's platform service fees, and Uber would declare comprehensive individual income tax for designated drivers by the end of the year based on the revenue sharing percentage of taxi rental operators and designated drivers.

\subsubsection{Influence of Amendments of Regulations for Automobile Transportation Operators on Passenger Car Rental Industry}

The amendment of Regulations for Automobile Transportation Operators came into effect in October2019, which regulated that the fare could only be charged for over 1 hour and cannot be evaded in any form if in the cooperation business model of passenger car rental practitioners and online car-hailing platforms (Article 103-1 of Regulations for Automobile Transportation Operators). Moreover, passenger car rental practitioners have to submit operation planning, the list of drivers to participate in the cooperation and the list of vehicles that they drive if they mean to work with online car-hailing platform practitioners. The special certificate label would be issued by authorities after the examination and approval of Directorate General of Highways while the dedicated label was required to be attached to the windshield of rental passenger cars for the inspection of passengers, highway authorities, police departments (Laws and Regulations Database, 2020). As a result, rental practitioners that work with online car-hailing platforms could only provide airport pick-up services instead of urban passenger transport services, which greatly influenced passenger car rental practitioners and drivers.

\subsection{Influence of Online Car-hailing Platforms on Taxi Passenger Transport Industry}

As for whether online car-hailing platforms did have an impact on taxi passenger transport service industry and how much the impact was, Practitioner A suggested that there was no valid data since most taxi passenger transport practitioners got paid in cash in most cases while only drivers dispatched by car agencies could leave some records if they get paid via e-payment. In this context, whether taxi 
drivers get more or less revenue is judged by the account of taxi drivers themselves. Therefore, to deal with the revenue of the taxi passenger transport industry, this study used the collected data from Ministry of Transportation and Communications, Taiwan, R.O.C (2020) for 2013, 2015, and 2017, respectively. In terms of taxi passenger transport service industry, this study took the listed Taiwan Taxi Co., Ltd as an example for case study.

\subsubsection{Influence on the Revenue of the Taxi Passenger Transport Industry}

After the entry of the online car-hailing platform Uber (hereinafter referred to as Uber for short) in 2012, it first cooperated with private cars (commonly known as white-label taxis), causing a great impact on the taxi industry as claimed by taxi drivers. The president of Taipei Professional Automobile Drivers' Union Li-Chia Cheng suggested that the revenue of taxi drivers had dropped $35 \%$ due to the cooperation between Uber and the passenger car rental industry (Tsao, 2018). The Department of Statistics, Ministry of Transportation and Communications, surveys the taxi industry biennially. Due to the unfinished survey in 2019 and Uber's entry into Taiwan in 2013, this study could only use existing data for subsequent research. From 2013 to 2017, Uber investigated in this paper had operated illegally for its use of white-label taxis (common name for illegally unregistered taxi cars). During this period, Taiwan Uber's operation cost was supposed to be the lowest and the number of vehicles shall be the highest because of its low entry standard. On the other hand, the current data did not reveal that the revenue of taxi drivers witness significant fluctuations and even dropped $35 \%$ as said by Li-Chia Cheng.

\subsubsection{Revenue Analysis of the Taxi Passenger Transport Service Industry}

The Department of Statistics, Ministry of Transportation and Communications, and other government agencies did not conduct substantial investigations, so this research took the largest Taiwan-based taxi passenger service provider Taiwan Taxi Co., Ltd (hereinafter referred to as Taiwan Taxi for short) as a case study. Being a listed company, the researcher was able to get its open and accessible financial report, so Taiwan Taxi's annual revenue of financial reports could be quoted to analyze and investigate the emergence of the online car-hailing platform Uber. According to the revenue of the online car-hailing platform Uber after entering into Taiwan in 2012 as listed in the Simplified Statement of Comprehensive Income-International Financial Reporting Standards (consolidated) included in the annual report to Taiwan Taxi shareholders, the revenue kept growing except that it decreased in 2016 compared with 2015. Whether such an increase was brought by online car-hailing platforms to the taxi passenger transport service industry deserves further discussion. However, as Taiwan Taxi is the leading Taiwan-based taxi passenger service provider, which has a much higher reputation than its peers, the result about whether it was influenced by online car-hailing platforms in terms of its revenue changes was not as significant as expected. In addition, its investment and operation projects could 
also bring revenue. Despite this, it would be more difficult to explore whether other small local car agencies were influenced by those platforms because the detailed and valid data were hard to collect.

\subsubsection{Influence of the Emergence of Ride-Hailing Platforms on the Number of the Taxi Passenger Transport Service Providers}

No obvious effects caused by online car-hailing platforms were found by only referring to the revenues of taxi drivers and the taxi passenger transport service industry. The total taxi number for each year collected by Statistics Network of Directorate General of Highways showed that the total number did not present a significant change except for a notable increase from September 2019 as many passenger car rental drivers switched to the taxi industry due to the amendment of Regulations for Automobile Transportation Operators. Moreover, the proportion of individual taxi passenger transport service providers is lowering each year. According to the data from Ministry of Transportation and Communications, Taiwan, R.O.C (2020) in 2017, only $40.5 \%$ of individual drivers joined car agencies. Its annual survey in 2017 also indicated that drivers who joined car agencies made NT $\$ 50,951$ monthly while those who did not earn a monthly income of NT $\$ 40,432$. That is to say, the former made $26 \%$ more than the latter monthly, which was a huge difference. Further investigation indicated that $34.8 \%$ of individual taxi passenger practitioners participated in car agencies in 2011, with $35 \%$ in 2013 and 51\% in 2015, respectively. In 2015, the national average revenue of the taxi passenger transport industry was the highest during the investigated years. It seemed that the most deciding factor that influenced taxi passenger practitioners lied in whether they joined car agencies.

Moreover, when online car-hailing platforms emerged, the proportion of individual taxi passenger transport service providers decreased, but the data analysis did not show significant relationship between them. However, the number of those who were both taxi passenger practitioner and taxi passenger service providers was growing year by year. Its change was compared and contrasted with license plates costs, an annual expenditure item of Taiwan Taxi Co., Ltd, finding that those who were both taxi passenger practitioners and taxi passenger transport service providers should purchase taxi license plates in the market to be qualified to provide one-stop driving service for people.

\subsubsection{Qualification of Taxi Drivers and Passenger Car Rental Practitioners}

Both the drivers of the taxi passenger transport industry and the passenger car rental industry shall obtain professional driving licenses (referred to as professional licenses for short), while professional taxi drivers are also required to obtain taxi registration certificates. Taxi passenger transport service providers could only be operated within the approved service area according to Highway Act while passenger car rental practitioners are spared such limitations. To be taxi drivers, people have to take a registration certificate examination for certain certificated area held by National Police Agency, and the examination content 
would be focused on the geographical environment and traffic regulations of the area. Designated drivers for rental passenger cars could provide passenger with ride services simply with professional driving licenses; they are not required to take such an examination. By analysis, it may due to the fact that the passengers of taxi drivers used to be roadside passers-by, so taxi drivers had to be familiar with the surrounding environment to reach the destinations in time. By contrast, the passenger car drivers could arrange the driving route in advance via GPS since their customers all used an appointment system.

\subsubsection{Conflicts of Taxi Passenger Transport and Passenger Car Rental Practitioners}

Taxi passenger transport practitioners protested against the involvement of the passenger car rental industry in the similar business through the cooperation between online car-hailing platforms and the passenger car rental industry. However, Article 91 of Regulations for Automobile Transportation Operators (2020) was modified to ease the limitations of taxis by Ministry of Transportation and Communications, Taiwan, R.O.C on Sep 1 ${ }^{\text {st }}$, 2017, which stipulated that 9-seat minibuses would be permitted to be used as taxis to carry passengers. However, the fare shall be limited to metered charges or be charged based on the mileage calculated by ride-hailing apps if involved vehicles participated in the "diversified taxis". However, nine-seat and seven-seat vehicles are often charted to passengers. Would this practice encroach on the business of passenger car rental practitioners? Ministry of Transportation and Communications eased the limitations so that nine-seat minibuses can operate as taxis, which did not conform to the separate management of different industries. The adjustment would end up with fiercer competition that passenger car rental practitioners would face. If the government bids for nine-seat vehicles and some are open to both passenger car rental and taxi passenger transport service providers, taxi service practitioners would be at an advantage due to the exemption from vehicle license and fuel tax. Could such a competition be called fair or be at the same starting point for the bidders in this context?

Passenger car rental and taxi passenger transport industry are both consumer-oriented and have different strengths. When operating under the existing law, as long as the limitations are eased, the whole transportation industry would have a positive impact from the introduction of diversified taxis and the permission of 9-seat vans to operate as taxis. Therefore, passenger car rental practitioners would face stronger competition, which would lead to better service quality. However, the current situation is that more limitations are eased whereas more restrictions are imposed at the same time. The former is called loosened restrictions and being more diversified, while the latter is named classified management and law-based administration. If Ministry of Transportation and Communications acknowledges the cooperation between the passenger car rental industry and online car-hailing platforms after the implementation of Article 103-1 of Regulations for Automobile Transportation Operators, how could such 
cooperation be defined as illegal before the amendment? Moreover, simply referring to the analysis of existing literature and related information, it is still unable to investigate the actual influence of the cooperation between the passenger car rental industry and online car-hailing platforms on the taxi passenger transport industry. There is no significant decline in the revenue of taxi service providers based on existing survey data, and the leading brand of the taxi passenger transport service industry Taiwan Taxi is not affected obviously. After the amendment of the law, it was obvious that the transfer of a number of passenger car rental practitioners to taxi passenger transport industry led to a record high of the number of taxis for the past eight years. Whether the beneficiaries of the amendment are existing taxi drivers or taxi passenger transport practitioners and taxi passenger transport service providers is worth observation and exploration.

\section{Results and Discussion}

\subsection{Modification of Relevant Issues on Regulations for Automobile Transport Industry}

Although Regulations for Automobile Transportation Operators was authorized by Highway Act, ambiguities still exist in its provisions, raising practitioners' doubts or leading them to have found out ways to evade the law without punishment. Based on the above research and interviews, several problems for two practitioners are summarized.

\subsubsection{Taxi Passenger Transport Practitioners}

Adhering to the issuing regulations of taxi license plates based on Article 39-1 of Highway Act, one is permitted to apply for the qualification as an individual taxi passenger transport service provider if he/she has the qualifications stipulated as Article 92 of Regulations for Automobile Transportation Operators, and holds no records of violation of laws as listed in Article 93 (for which he/she is eligible to be recognized as an excellent driver): ... Subparagraph Two: One holds a valid passenger car registration certificate continuously for more than six years; if their certificates are re-examined and changed based on Article 12 of Regulations for General Light Passenger Vehicle Registration Certificate, they are regarded as continuously holding the certificates, while the break period shall be subtracted... Article 91-2: Taxi license plates shall be issued according to the ratio of the population growth of a county or a city and its road area growth. The distribution baseline of the population shall be specified and announced by the central and municipal highway authorities in response to the transport demand within their jurisdiction (Laws and Regulations Database, 2020). When old taxis shall be replaced by new ones, within the baseline of the first article about the issuance of license plates, the ownership shall be transferred across administrative districts with the approval of both involved highway authorities after the report of both taxi passenger transport business and the trade union. Without control on the total amount for the individual taxi transport industry, Article 91-2 exists in name only 
practically. Cross-district transfer of ownership of taxi license plates was stipulated because Ministry of Transportation and Communications hoped to assist Uber in transferring from the passenger car rental industry into the taxi industry in 2019, for some local license plates were rented and charged at a high cost or kept without using and to deal with the issues caused by the transfer from the passenger car rental industry to the taxi passenger transport industry. The regulations indicated that the cross-district transfer of ownership shall be carried under the first principle above. Did this represent that there was still room to increase the number of local license plates issued based on the proportion of the population and the road area. If so, what was the reason for the cross-district transfer of ownership? Whether opening cross-district transfer of ownership deviated from the basic principles of issuing taxi license plates based on the proportion of the population and the road area for each county or city?

Tsai (2015) pointed out that the utilization rate of public transport and the population both had a positive effect on the number of taxis. Did that indicate there would be multiple considerations when it comes to the principles of issuing taxi license plates stipulated in Highway Act? Based on the data from Ministry of Transportation and Communications, Taiwan, R.O.C (2020), the total registration number of vehicle license plates for the taxi passenger transport industry by April of 2020 is 49,990 with those who are also taxi passenger service providers included, and that of taxi transportation cooperatives is 18,984. In addition, individual taxi passenger transport practitioners arrive at 23,701, which accounts for $25 \%$ of the total listed taxis, the lowest proportion in recent years; the highest had reached $32 \%$ before. Currently, the total listing number of taxis has hit the record high since 2012.If the loophole in the qualification review of individual taxi passenger service providers does not close, more drivers would be qualified to switch to the individual taxi passenger transport industry, which may result in an increase the proportion of individual taxis. Since the management of qualification application must be adjusted, it is suggested that the taxi passenger transport industry, whether for rental cars or affiliated vehicles, should hand in the liability of the traffic ticket to the supervision station to correct this issue. However, the solution still needs to be explored to cope with those who pretend to be employed by a taxi passenger transport agency with an intention to acquire the eligibility to join in the individual taxi passenger transport industry.

\subsubsection{Passenger Car Rental Practitioners}

Article 34 of Highway Act, Subparagraph Five stipulates: "The passenger car rental industry refers to those who operate businesses by renting the passenger cars or small-sized vans to their customers for their use ..." and Article 100 of Regulations for Automobile Transportation Operators, Subparagraph Two stipulates: "If the lessee of passenger car rentals needs to hire a driver, the lessor shall be responsible for hiring one that has the professional passenger car driving license for the lessee. For those who are foreign lessees, the designated driver shall be in a good command of the foreign language..." However, the business 
model stipulated in Highway Act has enabled passenger car rental practitioners to step into ride services due to the amendment of Regulations for Automobile Transportation Operators. Kwo-Tsai Wang, then Deputy Minister of Transportation and Communications, said on April 23 ${ }^{\text {rd }}$, 2019: "Two years ago, when Uber dispatched white-label cars to carry passengers, Ministry of Transportation and Communications got an idea - at present, there are a number of dispatch system for taxis while only a few systems for rentals. Similarly, there are more ride-hailing systems for taxis than for car rentals. That is why the Ministry hoped to transfer Uber to car rentals and Uber was subjected to current regulations and management rules for car rentals to charge fares by hour and by day. In this way, we hope that Uber could play an important role in a market of 170,000 rental cars. On the contrary, Uber meant to operate car rentals in the way taxis do. Without control on rental car license plates and fare rate, Uber grew very fast. Such a cross-industry operation made the game rules unfair. Two years ago, the Ministry wanted Uber to act as a car rental platform instead of a car-hailing platform" (Li, 2019). According to the regulations of car rentals as stipulated in Highway Act and Regulations for Automobile Transportation Operators before the amendment, there is no article to mention current fare charging shall be by hour and day as claimed by Deputy Minister Wang. Only the minimum duration of one hour for vehicle rent was referred to in Passenger Car Rental Standard Contract on Items That Should and Should not be Recorded and Passenger Car Rental Standard Contract Template. However, from the perspective of consumers, in accordance to Article 17 of Consumer Protection Law: To avoid consumption disputes and protect consumers' interests and rights, Passenger Car Rental Standard Contract on the Items that Should and Should not Be Recorded for the specific industry shall be formulated to promote the equality of standard contracts. Therefore, trade unions for each region publish Passenger Car Rental Standard Contract on the Items that Should and Should not Be Recorded and Passenger Car Rental Standard Contract Template, which declared the minimum duration of one-hour rent (Laws and Regulations Database, 2020).

The taxi passenger transport service industry is governed by the regulations on its dispatching platforms whereas passenger car rental practitioners were not limited by similar regulations. Therefore, the public called for the regulations on online car-hailing services. However, the Ministry of Communication and Transportation responded to them with the regulations on diversified taxis. The designated driving of the passenger car rental industry is a commercial behavior while the taxi passenger transport industry is part of mass transit; they are of different nature. Taxis could enjoy a tax exemption on the license and fuel. Moreover, according to No.841618025 Regulations by the Ministry of Finance, Taiwan published on April $24^{\text {th }}, 1995$, taxi drivers do not need operation registration and business tax and profit-seeking enterprise income tax compared with the individual taxi passenger transport. According to the turnover standard determined by tax authorities, profit-seeking enterprise income tax shall be calculated based on written reviews. After that, business income is calculated according to the net profit rate of the 
implementation points of declaration cases, based on which individual comprehensive income tax is levied. However, the passenger car rental industry, online car-hailing platforms, and designated drivers shall pay the tax according to the law. Taxis and others are of different nature. If the same business model applied to them could spare governments the burden to subsidize the taxi industry, provide additional tax to the government and offer another choice for consumers, why did the Ministry insist on pushing passenger car rental practitioners and online car-hailing platforms towards the scheme of diversified taxis? In June 2019, Ministry of Transportation and Communications added some provisions to Article 103-1 in Regulations for Automobile Transportation Operators(Laws and Regulations Database, 2020), which stipulated the minimum one-hour rent duration. Does this regulation ignore consumers' rights for other better contractual options? Simply seen from the above discussion on those two industries in this study, there were already ways to evade some conflicts between regulations and management rules or between the regulations and practice. Regulations for Automobile Transportation Operators are still applicable to sightseeing vehicles, automobiles for cargo shipping, and passenger car rentals. Even though this research does not touch on other subordinate industries ruled by Regulations for Automobile Transportation Operators, it deserves further discussion on whether to enhance the legal status of Regulations for Automobile Transportation Operators and modify the outdated articles above so as to improve the whole industry.

\subsubsection{Control on License Plates of the Taxi Passenger Transport Industry}

The Article 6 of Automobile Transportation Industry Audit Rules stipulates: "If taxi passenger transport practitioners are unable to replace the outdated vehicle with a new one within three years starting from the day the license plate is canceled, they are entitled to apply for the extension before the expiration of the term. The duration and times of extension shall be certified by the original highway authorities based on local transport demands and car agency management for future cancellation and replacement when the extension expires" (Laws and Regulations Database, 2020). The application for the extension and replacement of license plates and the repeated cancellation could lengthen the holding period of license plates. Thus, an excessive number of license plates are issued. In this respect, it is recommended to explore the market withdrawal mechanism of license plates for taxi passenger practitioners instead of unlimited extension as stated above.

\subsubsection{Substantive Control Issues of Taxi Transportation Cooperatives}

At present, taxi transportation cooperatives are always set at the same place with taxi passenger transport agencies. Moreover, the immediate family member of the transportation cooperative's president is often responsible for the taxi passenger transport agency. In this respect, it could be drawn up that taxi transportation cooperatives had long been dominated by taxi passenger transport practitioners; the government's good intention to open the establishment of the cooperatives 
fails to become a reality.

\subsection{Improvement on the Passenger Car Rental Industry and Establishment of Higher Standards for the Qualification Acquisition of Designated Drivers}

As a commercial act, those who engage in passenger transportation should be authorized and regulated by the nation. The taxi passenger transport industry is subject to the management of National Police Agency. It is suggested that designated drivers of passenger car rental practitioners should also be managed by the authorities who could provide an electronic login system for the practitioners to upload the data of their designated drivers for management. Due to the differences between passenger car rental and taxi passenger transport industries, the financial status of those who intend to operate passenger car rental industry by hiring designated drivers shall be certified by an accountant, or the capital limit of passenger car rental industry should be raised against the establishment of ready-made companies to prevent passenger car rental practitioners from establishing multiple branches. To better manage the designated drivers in the passenger car rental industry, it is suggested that passenger car rental practitioners shall provide relevant driving training certified by domestic training institutions; only the designated drivers with driving training could be permitted to carry passengers. Moreover, it is advised to set up technical skill tests to improve the qualification of designated drivers for the passenger car rental industry so that they can be distinguished more clearly from taxi drivers.

\subsection{Re-discussion on Relevant Rules of Diversified Taxis}

Although the diversified taxi is regarded as a solution to the online ride-hailing platform Uber, I think the diversified taxi is just a simplified version of the taxi with multiple limitations that are not able to meet actual needs imposed on it. Instead of attracting roadside passers-by and operating on fixed places and schedules, the diversified taxi could only carry passengers through prior reservation on the app. With current technology, it is easy to verify the identity of drivers at random via face recognition. Moreover, as for passengers, they could recognize drivers from their photos on mobile apps easily, rather than relying on the registration certificate photos of drivers after getting in the taxi. In addition, the driving route could be recorded by car agencies. Therefore, it is suggested that the limitation on diversified taxis shall be eased and non-commercial uses of the vehicle should be permitted with passenger attraction on tour still forbidden. Since diversified taxis can only be called through mobile apps, the data of turnover are all available. To avoid the situation that some pretend to operate as diversified taxis for license and fuel tax exemption, it is suggested that such an operation could be labeled as tax evasion if their annual turnover is less than a certain amount and the license and fuel taxes should be recollected. The diversified taxi shall not simply be a simplified version of taxi, and the qualification of the diversified taxi drivers shall be the same to that of taxi drivers except that they do not have to use the color of yellow like taxis. The original taxi business model is 
suggested to be abandoned and the diversified taxis should be given more functions, such as friends and relatives driving the vehicle, making them actually "diversified".

\subsection{Suggestions on the Cooperation between Passenger Car Rental Industry and Taxi Passenger Transport Industry}

The taxi passenger transport practitioners should have adopted mileage-based charging, but they often operate tour chartered businesses in major scenic spots. Currently, the restriction on vehicle types has been loosened in the taxi passenger transport industry, but the commercial behaviors of cross-district operation and non-mileage-based charging are still not permitted. It is suggested that taxi drivers work with passenger car rental practitioners and operate as a short-term rental with a designated driver if there are services such as chartered vehicle service and cross-district shuttle service, rather than adopting cross-district operation with non-mileage-based charging.

\subsection{Follow-up Research and Suggestion}

\subsubsection{Follow-up Analysis of Taxi Drivers' Revenue}

As for whether the transfer of Uber to the taxi passenger transport industry due to Article 103-1 of Regulations for Automobile Transportation Operators affected existing drivers' revenue, subsequent research is advised to be carried out in terms of the revenue of diversified taxis and traditional taxis.

\subsubsection{The Following Influence of Online Car-hailing Platforms on the Taxi Passenger Transport Industry and Passenger Car Rental Industry}

Since 2020, passenger car rental drivers in cooperation with online car-hailing platforms have started to transfer to the taxi passenger transport industry. It should have been possible to explore the subsequent industrial development and changes. However, Taiwan tourism industry suffers from great losses due to the outbreak of COVID-19, so do the transportation practitioners. The passenger car rental and taxi passenger transport industries are both greatly influenced. After the COVID-19 ends, and the supply and demand of the industry rebalances, the follow-up research is suggested to explore the influence of the entry of online car-hailing platforms into the taxi passenger transport industry and the operating model of passenger car rental practitioners in cooperation with online car-hailing platforms. 


\section{References}

[1] Bureau of Transportation, Kaohsiung City Government (2020).

Charging Standard of Each Fleet in the City. Available from: https://www.tbkc.gov.tw/Service/PublicTransport/Taxis?ID=26d69492-85044fab-97b0-babd3bfee2e4

[2] Carnews (2019). Obey the Law, Never Stop Innovation, JoinMe Claims to Postpone the Real-time Car-hailing Service, Carnews. Available from: https://carnews.com/article/info/8147a542-6b27-11e9-b3f3-42010af00004?pr eview $=1$

[3] Chen, P., Chou, W. and Shi, X. (2017). Exploration on Emerging Managerial Issues of Taxi Operation Model, 2017 Seminar on Road Traffic Safety and Law Enforcement, 531-546.

[4] Chang, Y. (1999). Transportation, Taipei: Hwa Tai Publishing Co., Ltd.

[5] CTCI Foundation (2019). The Impact on the Rise of Platform Economy for Industry Development and Resource Utilization, Special Report. Available from: https://www.ctci.org.tw/8838/research/26382/41138/

[6] Eisenhardt, K. (1989). Building Theories from Case Study Research, Academy of Management Journal, 14(4), 532-550.

[7] Gu, S. (2015). At no Cost, Defeat the Big Consortium, Common Wealth Magazine. Available from: https://www.cw.com.tw/article/5072294

[8] Huang Y. (2019). I'm Legal Again; I'm Illegal Again-National Taiwan University Events of Uber, Up Media. Available from: https://www.upmedia.mg/news_info.php?SerialNo=64190

[9] Hou, S., Lien, W. and Chou, C. (2017). An Empirical Study on the Relationship between Service Inventory and Operational Performance: Taiwan Taxi Fleet Taken as an Example. NTU Management Review, 27(2), 63-92.

[10] Kang, T. and Huang, B. (2015). Exploring Taiwan SME Business Opportunities with the Development of Sharing Economy, Journal for SME Development, 36, 1-29.

[11] Kuo, P. and Chou, W. (2017). Challenges to Taxi and Car Rental Industry-A Review of Uber. Journal of Traffic Science, 17(1), 57-82.

[12] Laws and Regulations Database-Ministry of Justice, Taiwan, R.O.C (2020). Available from: https://law.moj.gov.tw/LawClass/LawParaDeatil.aspx?pcode=K0040003\&bp $=16$

[13] Li, T. (2019). Dispute on Management of Uber, Ministry of Transportation and Communication: Setting up a taxi fleet gives a way out, Apple daily. Available from: https://tw.appledaily.com/new/realtime/20190423/1555423/

[14] Ministry of Transportation and Communications, Taiwan, R.O.C (2020). Available from: https://stat.motc.gov.tw/mocdb/stmain.jsp?sys=100\&funid=defjsp

[15] Neuman, W. (2000). Social Research Methods Qualitative and Quantitative 
Approaches, 4th Edition, Allyn \& Bacon, Needham Heights.

[16] Peng, W. (2017). Exploration on Management Regulations of Car Rental Industry, Analysis issues of Legislative Yuan, R00592.

[17] Peng, W. (2018). Exploration on related disputes of automobile transportation industry, Analysis issues of Legislative Yuan, R00491.

[18] Tsai, Y. (2015). A Study of Factors Affecting Number of Taxi in Taiwan, thesis, Department of Transportation \& Logistics Management, National Chiao Tung University.

[19] Tsao, Y. (2018). Is Uber More Fashionable?"Blood and Tears" Behind the Protests of 3000 Taxi Drivers: Driving a Taxi to Supports a Home, EtToday. Available from: https://www.ettoday.net/news/20181106/1299378.htm

[20] Wei, K. (2019). Uber, the Diversified Taxis, Under the Gorgeous Sugar Coating is Still Poison, The News Lens. Available from: https://www.thenewslens.com/article/125633

[21] Wu, C. (2017). Cooperate with Fully Paid Taxes- Uber's New Model without Tax Owed , Liberty Times. Available from: https://ec.ltn.com.tw/article/breakingnews/2157029

[22] Wu, Y. (2019). Concession! Uber's Business Model is Turning, Changing to Cooperation with Multiple Taxis, Business Next. Available from: https://www.bnext.com.tw/article/54933/uber-taiwan-transform-model

[23] Yin, R. (1994). Case Study Research: Design and Methods, Beverly Hills, CA: Sage. 